\title{
THE WEIGHT IN PINK DISEASE
}

BY

\author{
T. COLVER \\ From the Sheffield Children's Hospital
}

(RECEIVED FOR PUBLICATION JUNE 14, 1955)

It is the object of this report to draw attention to the characteristic weight trends in pink disease. The characteristic trends are not described in writings on the subject, and they merit attention since weight is the only serial observation available which is strictly objective, easily measured and uninfluenced, as are blood pressure and pulse rate, by the unfamiliar surroundings of an out-patient clinic.

\section{Clinical Material}

The hundred patients under review attended a special weekly clinic, and the series was consecutive except for six babies who recovered within five weeks of the first hospital visit and two who attended very irregularly. Of 100 patients, 47 were male and 53 female, and the average age of onset was $7 \frac{1}{2}$ months. Two died, in the fourth and twelfth weeks of the disease respectively, and the average duration of the disease in the remainder was 17 weeks. Appointments at the clinic were occasionally not kept, but it was usually possible to rearrange a missed appointment within two or three days. Of the 903 appointments made, 22 were missed altogether.

\section{Management}

Management followed commonly accepted principles. In an attempt to avoid unnecessary loss of weight parents were asked to quench the infants' thirst with cold milk rather than watery drinks. Chloral, phenobarbitone, sulphonamides and antibiotics were commonly used, but instructions were given that other medicaments, particularly those containing mercury, should be avoided. At the clinic each week the baby was first weighed in its clothes, the latter being weighed separately, and each weighing was checked by physician and nurse.

\section{Serial Weight Records}

The percentage weight losses during observation are shown in Table 1. Eleven babies lost $11 \%$ or more of their body weight during observation, and the records of this minority will be examined in
TABLE 1

PERCENTAGE WEIGHT LOSS DURING OBSERVATION IN 98 PATIENTS

\begin{tabular}{c|c}
\hline Percentage Weight Loss & Number of Patients \\
\hline $0-0.9$ & 29 \\
$1-1.9$ & 6 \\
$2-2.9$ & 15 \\
$3-3.9$ & 9 \\
$4-4.9$ & 5 \\
$5-5.9$ & 6 \\
$6-6.9$ & 4 \\
$7-7.9$ & 4 \\
$8-8.9$ & 4 \\
$9-9.9$ & 1 \\
$10-10.9$ & 4 \\
$11-11.9$ & 4 \\
$12-12.9$ & 2 \\
$13-13.9$ & 3 \\
$14-14.9$ & 2 \\
$15-15.9$ & 2 \\
\hline
\end{tabular}

detail since they relate only to severe examples of the disease observed in the active as well as the later phases. These detailed records are, therefore, shown in Table 2, and in the diagram the curves for 10 of the patients are plotted. Three features common to each patient will be noted: $(a)$ an appreciable interval elapses between the onset of symptoms and the first hospital visit; (b) practically the whole observed weight loss occurs in one almost uninterrupted downward trend; and (c) this downward trend occurs in the early part of the observation period. For precision and to simplify comparison, these weight curves may be divided into initial, transitional and terminal stages. The transitional stage begins when the initial downward trend levels out and is defined as the first consecutive two-week period (indicated in Table 2 and in the diagram) in which there is no further overall loss of weight. The curves before and after this stage.comprise the initial and terminal stages. It is now seen that the weight at the bottom of the initial downward trend is to within an ounce or so, the lowest encountered observation, the curve after this point being mainly level or rising and certainly showing no further fall in any way comparable with the initial one (except in Baby 10 who had pneumonia resistant to antibiotics in the nineteenth week). The initial stages 
TABLE 2

SERIAL WEIGHT RECORDS (lb. oz.) OF 11 BABIES LOSING $11 \%$ OR MORE OF BODY WEIGHT

\begin{tabular}{|c|c|c|c|c|c|c|c|c|c|c|c|c|}
\hline $\begin{array}{c}\text { Duratio } \\
\text { of } \\
\text { Disease }\end{array}$ & & 1 & 2 & 3 & 4 & 5 & 6 & 7 & 8 & 9 & 10 & 11 \\
\hline 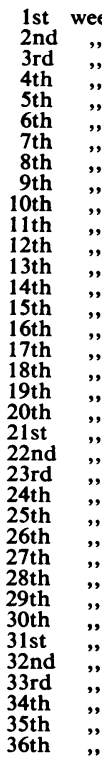 & ":"ek & $\left.\begin{array}{c}= \\
= \\
18-6 \\
17-14 \\
17-3 \\
17-0 \\
16-12 \\
16-15 \\
17-0 \\
17-7 \\
17-15 \\
18-8 \\
19-1 \\
19-12\end{array}\right\}^{*}$ & $\begin{array}{l}20-5 \\
20-5 \\
19-8 \\
18-15 \\
18-11 \\
18-5 \\
18-3 \\
18-1 \\
18-2 \\
18-1 \\
18-0 \\
18-8 \\
18-12 \\
18-9 \\
18-11 \\
19-3 \\
19-3 \\
19-9\end{array}$ & $\begin{array}{c}= \\
= \\
= \\
22-4 \\
21-8 \\
21-2 \\
20-8 \\
19-15 \\
20-7 \\
19-13 \\
19-6 \\
19-10 \\
19-13 \\
20-4 \\
20-3 \\
20-2 \\
20-5 \\
20-3 \\
20-6 \\
20-6 \\
20-3 \\
21-1 \\
21-4 \\
21-1 \\
21-12 \\
22-7 \\
22-13 \\
23-4 \\
23-4 \\
23-7 \\
24-5 \\
24-1 \\
24-8\end{array}$ & $\begin{array}{c}= \\
22-3 \\
21-9 \\
21-3 \\
20-12 \\
20-10 \\
20-10 \\
20-5 \\
19-14 \\
20-5 \\
20-11 \\
21-3 \\
21-9 \\
21-15 \\
22-17 \\
22-10\end{array}$ & $\begin{array}{c}\overline{-} \\
16-14 \\
15-9 \\
15-5 \\
14-13 \\
14-5 \\
14-12 \\
14-13 \\
14-14 \\
14-6 \\
15-6 \\
16-3 \\
17-1 \\
18-0\end{array}$ & $\begin{array}{c}= \\
\bar{Z} \\
\bar{z} \\
17-13 \\
17--8 \\
16-13 \\
16-6 \\
16-5 \\
16-13 \\
17-3 \\
17-8 \\
18-0 \\
18-8 \\
19-3 \\
19-13 \\
19-13 \\
19-11\end{array}$ & $\begin{array}{c}\bar{Z} \\
\bar{Z} \\
22-11 \\
21-13 \\
21-8 \\
20-10 \\
20-11 \\
20-13 \\
20-12 \\
20-11 \\
21-9 \\
22-9 \\
22-7 \\
22-11 \\
22-11\end{array}$ & $\begin{array}{c}= \\
\bar{Z} \\
= \\
\bar{Z} \\
21-1 \\
20-5 \\
20-0 \\
19-9 \\
19-11 \\
19-9 \\
19-15 \\
19-6 \\
20-3 \\
20-8 \\
20-13 \\
20-11 \\
20-9 \\
21-6 \\
21-11 \\
22-9\end{array}$ & $\begin{array}{c}= \\
= \\
= \\
\bar{z} \\
16-10 \\
16-6 \\
16-5 \\
15-12 \\
15-15 \\
15-2 \\
14-14 \\
15-3 \\
15-5 \\
15-4 \\
15-6 \\
15-3 \\
15-6 \\
15-3 \\
15-15 \\
15-13 \\
15-7 \\
15-9\end{array}$ & 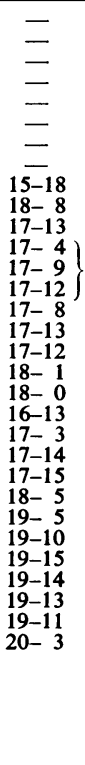 & 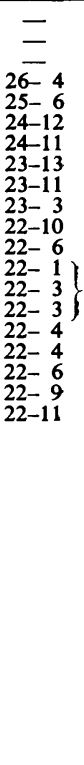 \\
\hline
\end{tabular}

* Transitional stage indicated in each case.

of the Table 2 group lasted on average until the tenth week of the disease (average weekly change $=$ $7 \cdot 5 \mathrm{oz}$. fall) and the average duration of the terminal stages was 10 weeks (average weekly change = $4 \cdot 7 \mathrm{oz}$. rise). The form of the curves before the first hospital visits was not, of course, known, but the downward trend presumably began early, and this presumption was repeatedly confirmed by records generously supplied by Dr. K. Black, of the Maternity and Child Welfare Department of Sheffield (by courtesy of Dr. L. Roberts, Medical Officer of Health). In one patient (not of the Table 2 group) the curve was unusual in that the downward trend was delayed until the third week of hospital observation.

In short, the weight curve in pink disease consists of an early progressive trend downwards, which, once completed according to the above definition, does not show recurrences.

\section{Comment}

The weight curves in the diagram contrast with those commonly seen in out-patient practice since the initial down trends are not usually so marked. Thirteen per cent. of the present entire series did, in fact, show no weight loss at all during observation, but in these patients it is believed that the initial trend downwards had already occurred before the first hospital visit. There is usually considerable delay before the infants come under observation (Table 3), and it is readily understood that much or all of the initial down trend may take place during this interval, particularly if it is long or the period of fall in weight short.

TABLE 3

DURATION OF PINK DISEASE BEFORE FIRST HOSPITAL VISIT IN 100 PATIENTS

\begin{tabular}{|c|c|c|c|c|c|c|}
\hline Weeks & & & & & & Number of Patients \\
\hline $\begin{array}{r}1 \\
2 \\
3 \\
4 \\
5 \\
6 \\
7 \\
8 \\
9 \\
10 \\
11 \\
12 \\
13 \\
14 \\
15 \\
16 \\
17\end{array}$ & $\begin{array}{l}\because \\
\because \\
\because \\
\because \\
\because \\
\because \\
\because \\
\because \\
\because \\
\because \\
\because \\
\therefore\end{array}$ & $\begin{array}{l}\because \\
\because \\
\because \\
\cdots \\
\because \\
\because \\
\because \\
\because \\
\because \\
\because \\
\because \\
\cdots\end{array}$ & $\begin{array}{l}. \\
\therefore \\
\therefore \\
\therefore \\
\therefore \\
\therefore \\
\therefore \\
\therefore \\
\therefore \\
\therefore\end{array}$ & $\begin{array}{l}\because \\
\because \\
\because \\
\because \\
\because \\
\because \\
\because \\
\because \\
\because \\
\because \\
\because \\
\because\end{array}$ & $\begin{array}{l}\because \\
\because \\
\because \\
\cdots \\
\because \\
\because \\
\because \\
\because \\
\because \\
\because \\
\because \\
.\end{array}$ & $\begin{array}{r}2 \\
8 \\
15 \\
16 \\
13 \\
15 \\
8 \\
8 \\
3 \\
0 \\
7 \\
3 \\
0 \\
0 \\
0 \\
1 \\
1\end{array}$ \\
\hline
\end{tabular}




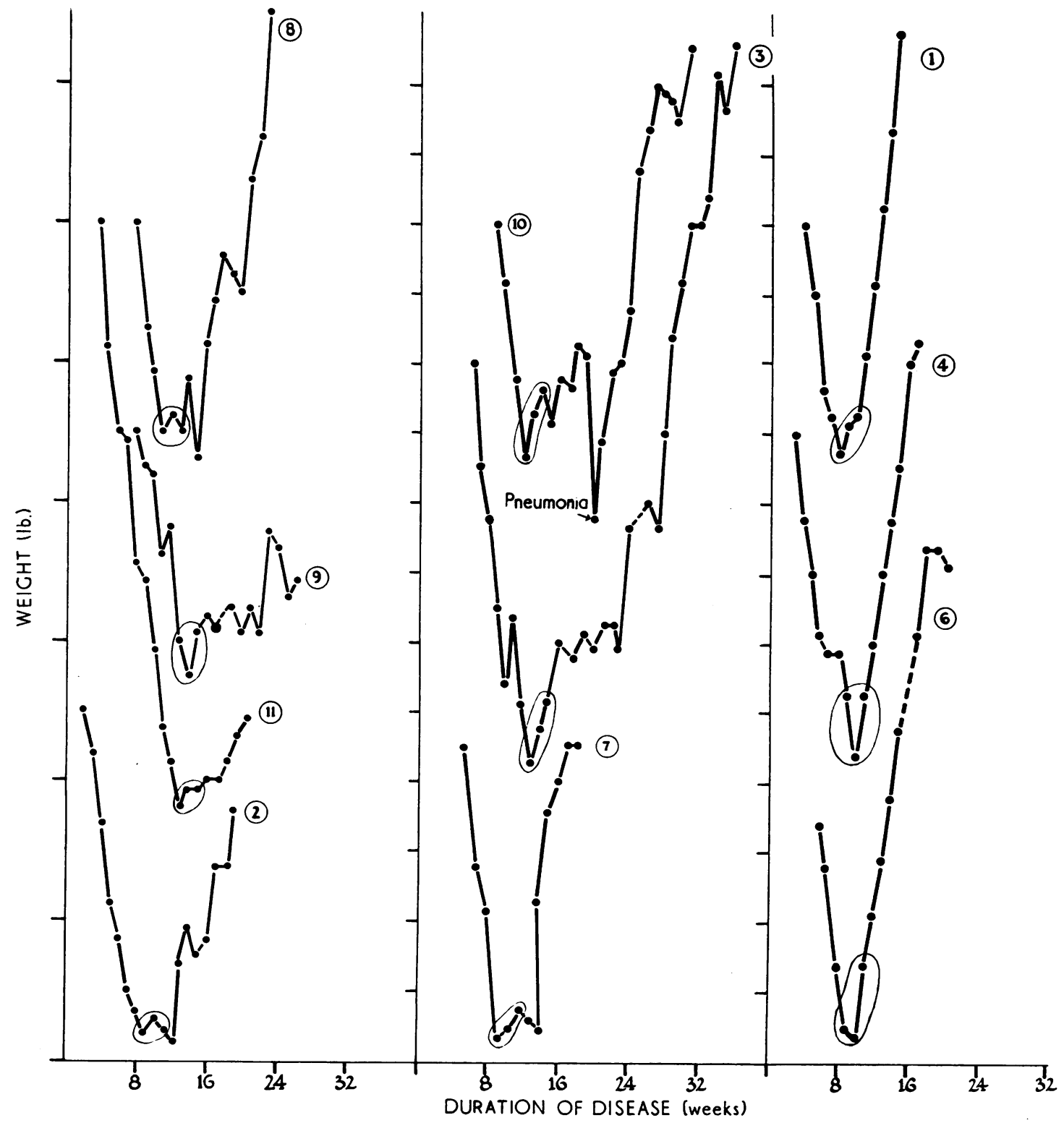

The_weight curves for 10 of the 11 patients who, during observation, lost $11 \%$ or more of their body weight. The intermediate stage is indicated on each curve.

\section{Correlation of Weight Curve with General Condition}

The weight curves presumably reflect the underlying general clinical condition, but since the value of recording weight hinges on this presumption, corroboration is required. This is available to the extent that each week before the weighing records were separately kept of (a) the general appearances of the patient, (b) the gist of the mother's weekly progress reports and (c) the variation of individual features such as photophobia. The records cannot be shown for all cases, but a typical series is shown in Table 4.

Of the two sets of records, the mother's progress 
reports are the more valuable. She alone knows the prevailing temperament and capacity to eat, sleep and take interest. The clinician's gradings, moreover, were unavoidably very coarse, but both sets of records point to complete refractoriness of general symptoms during the stage of falling weight and to the absence of relapse thereafter. The mothers' reports particularly emphasize the abruptness of the transition (the 'turn' in the parlance of many Sheffield mothers) from the initial refractory to the recovery phases. For week after week at first, the mother reports, 'He is no better'. Then there comes the week when the clinician can predict from her more cheerful expression, though not necessarily from the baby's appearance, that the 'turn' has come.

Individual Symptoms. In judging general progress the fluctuations of the more specific individual features such as photophobia were often misleading. These special features did, however, follow a particular pattern of their own which in its turn showed some correlation with the clinical stages described. At the onset of the disease it is known, for instance, that the diagnosis may not be clear, particularly if the characteristic photophobia and rash are absent and if the general symptoms are mild. The typical extremity changes, emaciation and profound hypotonia, do not, moreover, ordinarily develop for a few weeks. During the first stage diagnosis becomes easier since all features initially present become more marked and others, such as the typical changes of the extremities, make their appearance, the clinical picture gradually reaching its most florid state just before the 'turn'. Particularly at the end of this first stage the picture is dominated by general misery and debility, profound emaciation, hypotonia and extremity changes, together with photophobia and rash in classical cases. At the 'turn' there is an abrupt dissociation of clinical features, and the mother is aware of a sudden substantial improvement in temperament, even though the physical appearance of the infant remains much the same. During the recovery stage all features may henceforth improve pari passu, but sometimes, particularly in long-term cases, the dissociation described becomes more extreme, the general symptoms of irritability and misery clearing much faster than, for instance, the hypotonia. This gives rise to a clinical picture not unlike amyotonia congenita (Leys, 1950).

\section{Implications}

Therapeutic Trials. The existence of the twostage course, with its progressive recovery phase, emphasizes the need for proper control during therapeutic trials and throws open to criticism most, if not all, of the trials hitherto reported in this condition. In the total series of 100 patients, for instance, the average interval between the onset of the disease and the first hospital visit was nearly six weeks (Table 1). The average interval between the onset and the beginning of the recovery phase for the 98 remaining patients was seven weeks. Improvement is to be expected, therefore, in the average hospital patient, one week after the first hospital visit regardless of the form of treatment.

Prognosis. The strain and worry imposed on the mothers of these patients is familiar and the physician gives what reassurance he legitimately can. The greater predictability afforded by a knowledge of the foregoing trends helps him in this respect. In general, instead of just being able to tell the mother that the average duration for hospital patients is approximately four months (this was the figure in this series; see also Fisher, 1947) he can add that the worst of the disease is likely to be over in two months. He can also predict a progressive recovery phase as soon as there comes a period of two consecutive weeks with no overall weight loss.

TABLE 4

TYPICAL CORRELATION BETWEEN WEEKLY WEIGHT CHANGE, MOTHER'S PROGRESS REPORT AND THE CLINICIAN'S OBJECTIVE GRADINGS

\begin{tabular}{|c|c|c|c|c|c|c|c|c|c|c|c|c|c|c|c|c|c|}
\hline Duration of disease in weeks & . & 1 & 2 & 3 & 4 & 5 & 6 & 7 & 8 & 9 & 10 & 11 & 12 & 13 & 14 & 15 & 16 \\
\hline Weight change in ounces $\ldots$ & . & & & & -7 & -6 & -7 & -4 & -5 & +2 & +5 & +7 & +1 & +0 & +5 & +2 & +6 \\
\hline Mother's progress reports* .. & . & & & $\downarrow$ & $\downarrow$ & 0 & 0 & 0 & 0 & $\uparrow$ & $\uparrow$ & $\uparrow$ & $\uparrow$ & $\uparrow$ & 0 & $\uparrow$ & Recovery \\
\hline Clinician's objective $\nmid$ gradings & $\cdots$ & & & 3 & 3 & 3 & 3 & 3 & 3 & 3 & 2 & 2 & 2 & 2 & 2 & 1 & Recovery \\
\hline
\end{tabular}

* The symbols indicate: $\uparrow$ substantial improvement, $\downarrow$ substantial deterioration, and 0 no appreciable change, and the numbers $1,2,3$ and 4 the clinician's assessment of general condition as judged by general appearances.

Grade 4, severest grade, typical appearances, patient gravely ill and causing anxiety as to immediate survival, periods of prostration alternating with periods of typical irritability; Grade 3, typical appearances, inability to take interest and no smile, but no anxiety as to immediate survival; Grade 2, similar to Grade 3, except for short periods in which the baby takes a little interest in surroundings and in which it may smile for a few moments; Grade 1, mildest grade, clinician sees no satisfactory evidence of active disease, but the mother reports that the baby is not by any means recovered. 
Aetiology. The possible role of mercury as a cause of this disease is today constantly under discussion and any fresh impressions as to the natural course of the disease must be considered in this connexion. So far as they go the findings of this report support the mercury hypothesis: i.e., $(a)$ the older editions of the standard textbooks (Sheldon, 1946) emphasized the unpredictable ups and downs of the disease; $(b)$ this was the course to be expected if mercury were responsible and no steps were taken to withhold its further administration during treatment; $(c)$ in the series under review instructions were given that no further mercury should be taken during treatment and unpredictable ups and downs have been absent. The course has presented, on the contrary, just the pattern to be expected if mercury is responsible, i.e., an initial refractory phase until the bulk of the mercury has been excreted and thenceforth the progressive recovery phase to be expected once the metal has been removed.

\section{Summary}

The weight curve in pink disease may conveniently be considered in two distinct stages.
The initial stage consists of a progressive downward trend commonly lasting for eight weeks.

The terminal stage consists of a level or rising curve which is, barring intercurrent infection, free from any appreciable weight falls.

From the general clinical viewpoint, the main finding was the good correlation between weight and general condition with the conclusion that pink disease in all its aspects follows a two-stage course: an initial stage with active refractory symptoms and progressively falling weight, and one of recovery with gradual general improvement, a level or rising weight and no relapse.

I should like to thank Mr. A. S. Foster, medical artist to the United Sheffield Hospitals, for the diagram, and Dr. T. Lodge and Dr. J. C. Haworth for their criticism.

\section{REFERENCES}

Fisher, T. N. (1947). Brit. med. J., 1, 251.

Leys, D. (1950). Archives of Disease in Childhood 25, 302. Sheldon, W. (1946). Diseases of Infancy and Childhood, 5th ed., p. 556. Churchill, London. 